\title{
O LIBERTARIANISMO DE JONATHAN LOWE
}

\author{
Marco Oliveira ${ }^{1}$ \\ Universidade Federal do Rio de Janeiro (UFRJ) \\ (D) https://orcid.org/0000-0002-8149-3323
}

\begin{abstract}
RESUMO:
O objetivo deste artigo é apresentar a versão libertariana de Jonathan Lowe acerca da vontade livre. Ações intencionais são explicadas ao mencionarmos as razões pelas quais os agentes adotaram certos cursos de ações. Uma característica essencial dessas ações seria a capacidade de um agente de deliberar sobre as circunstâncias de um determinado curso de ação, antes de decidir o que fazer. A questão, na Filosofia da ação, é abordada por deterministas e seus opositores. Enquanto deterministas apresentam críticas contra a noção difundida pelo senso comum de que ações têm base no livre exercício da vontade, outros filósofos, como compatibilistas e libertarianistas, oferecem apoio a essa ideia. Libertarianistas, em especial, defendem que nós, como agentes livres, exercemos a vontade sem que eventos anteriores possam ser identificados como uma causa suficiente. Jonathan Lowe, em seu livro Personal Agency (2008), propôs uma nova versão dessa teoria, ao aliar nossa capacidade de decidir livremente como seres racionais com uma nova visão sobre a causação, a saber, a manifestação de poderes (e suscetibilidades) por substâncias. O exercício da vontade seria uma espécie de poder racional.
\end{abstract}

PALAVRAS-CHAVE: Vontade livre; Libertariansmo; Jonathan Lowe; Causação por agente; Causação por substância.

\section{JONATHAN LOWE'S LIBERTARIANISM}

\begin{abstract}
:
The aim of this article is to introduce Jonathan Lowe's version of libertarian free will. Intentional actions are explained when we point out the reasons why agents have taken certain courses of action. An essential feature of these actions would be the agent's ability to deliberate about the circumstances of a particular course of action, before deciding what to do.
\end{abstract}

\footnotetext{
${ }^{1}$ Doutorando em filosofia pela Universidade Federal do Rio de Janeiro (UFRJ), Rio de Janeiro - Brasil. E-mail marco.oliveira@ufrj.br
} 
The issue, in Philosophy of Action, is approached by determinists and their opponents. While determinists are critics of the common sense idea of an action being based on the free exercise of will, other philosophers, such as compatibilists and libertarianistas, offer support to this idea. In particular, Libertarianists argue that we, as free agents, exercise our will without the occurence of previous events that could be identified as a sufficient cause. Jonathan Lowe, in his book Personal Agency (2008), put forward a new version of this theory, by combining our ability to decide freely as rational beings with a new view of causation, namely, the manifestation of powers (and liabilities) by substances. The exercise of the will would be a kind of rational power.

KEYWORDS: Free will; Libertarianism; Jonathan Lowe; Agent causation; Substance causation.

\section{Introdução}

Abordaremos no artigo a versão do Libertarianismo apresentada por Jonathan Lowe em seu livro Personal Agency (2008). De forma simples, defensores do Libertarianismo acreditam que o exercício da vontade é incompatível com a determinação das nossas ações por eventos anteriores. É certo que algumas de nossas ações sofrem alguma determinação ou influência, mas, ao menos em certos casos, alguns filósofos acreditam que há um exercício genuíno da vontade.

O objetivo desse artigo é, simplesmente, apresentar os principais elementos da defesa da vontade livre por Jonathan Lowe, que incluem uma nova perspectiva sobre a causação, a saber, a causação por substância e a apresentação do ser humano como um agente que exerce a vontade através de um poder racional - em oposição a um poder causal.

Para explicar de forma suficiente a proposta desse autor, seria necessário tratar de outras questões próximas, como a agência humana racional $^{2}$, a recusa de razões como causas ${ }^{3}$, a defesa de um dualismo nãocartesiano ${ }^{4} \mathrm{e}$ argumentos contra o princípio de fechamento causal ${ }^{5}$. Contudo, abordaremos esses assuntos de forma breve e apenas como suporte para a argumentação central apresentada no texto.

2 Cf. LOWE, 2008, pp. 12, 116.

3 Cf. LOWE, 2008, pp. 116, 131, 154-157. Sobre esse aspecto, o autor identifica Donald Davidson como um autor que defende uma teoria oposta a sua. Retomaremos esse tema, de forma breve, em outro momento do artigo.

4 Cf. LOWE, 2008, p. cap. 5.

5 Cf. LOWE, 2008, cap. 2. Ao longo de sua argumentação, o autor solicita que tomemos como provável que o exercício da vontade seja independente de eventos anteriores suficientes para determinar as ações humanas. Cf. LOWE, 2008, p. 129. 


\title{
0 problema da vontade livre
}

A intuição de que as nossas ações são totalmente livres é vista por alguns como problemática face às novas descobertas científicas, que afirmam que nossas convicções morais, nossos gostos e valorações são apenas um produto da nossa biologia, aliada ao ambiente e à cultura na qual crescemos. Os valores que mantemos, por exemplo, seriam explicados pela época e cultura, aliados às nossas condições psicológicas, que são, por sua vez, também explicadas pela hereditariedade e pela nossa educação. Como todos esses fatores externos e internos a nossa psicologia são eventos que podem ser datados e localizados, há um grupo de filósofos que pretende explicar o mundo em termos dos eventos que causaram o atual estado de coisas.

Segue-se dessa linha de argumentação que nossas ações seriam apenas mais um elo em uma cadeira causal de eventos, explicadas por meio dos eventos que as precedem. De acordo com defensores do Determinismo (causal), então, é verdade que todo evento é suficientemente explicado pelos eventos que o precedem. Percebemos a força dessa afirmação quando esse fato não é entendido como mera contingência. Os eventos precedentes não apenas trazem à tona os eventos posteriores, mas eles também determinam quais eventos se seguirão. Na cadeia de explicações causais, não teríamos, então, bifurcações, mas apenas uma linha fixa de eventos causalmente determinados. Poderíamos, então, resumir a tese do Determinismo (causal) na seguinte afirmação: Todo evento é causalmente determinado por eventos precedentes, que explicam a sua ocorrência.

De acordo com Robert Kane, a ideia central que permeia todas as teorias determinísticas é ${ }^{6}$ :

\begin{abstract}
Um evento (tal como uma escolha ou ação) é determinado quando existem condições dadas anteriormente [...] cuja ocorrência é uma condição suficiente para a ocorrência do evento. Em outras palavras, tem de ser o caso que, se essas condições determinantes anteriores estão presentes, então o evento determinado ocorrerá. (KANE, 2005, p. 5-6, grifo do autor, tradução nossa)
\end{abstract}

Em questões mais simples como escolher filmes para assistir, em quem nós votaremos e outras preferências em geral, não percebemos o problema posto pelos deterministas e poucos diriam, também, que não sofremos qualquer influência ou que não lidamos com limitações em nossas

6 Em muitas passagem da argumentação de Jonathan Lowe, são justamente essas condições suficientes que ele supõe não estarem presentes no caso da ação racional ou livre. Cf., especialmente, LOWE, 2008, p. 129. 
escolhas. ${ }^{7}$ A questão é que mesmo nossas preferências e escolhas já são prédeterminadas por circunstâncias que não estão sob nosso domínio. De acordo com KANE (2005, p. 2, tradução nossa), “[n]ós seríamos livres para agir ou escolher o que nós [já] desejamos, mas não teríamos o poder último a respeito daquilo que nós desejamos". 8

A questão também pode ser colocada em termos do controle que os agentes possuem sobre suas ações. Existiriam dois modelos para interpretar as ações dos agentes nessa perspectiva: o das alternativas possíveis e o da origem. Em primeiro lugar, para que nossas ações sejam realmente livres, os efeitos das nossas ações não podem se restringir a uma única possibilidade, o futuro precisa estar aberto, de modo que um agente somente teria controle sobre suas ações se tiver a habilidade de escolher entre possíveis formas de realizar uma ação. ${ }^{9}$ Já na segunda perspectiva, os argumentos pretendem questionar o ponto de partida das nossas ações. A crítica determinística consiste em afirmar que, para cada ação, é possível encontrar uma causa originada fora do agente, ou seja, localiza-se uma condição necessária para a ação "em lugares e tempos antes do [ato do] agente querer livremente [realizar] sua ação." (MCKENNA \& COATES, 2015, tradução nossa) condições:

A ação livre dependeria, nesse sentido, da satisfação de duas

1. “o que nós escolhemos e como nós agimos depende de nós; e isso significa que poderíamos ter escolhido ou agido diferentemente" (KANE, 2005, p. 6, tradução nossa) e

2. "a fonte última das nossas ações situa-se em nós e não fora de nós, em fatores além do nosso controle." (KANE, 2005, p. 6 , tradução nossa)

Se as nossas ações futuras já estão determinadas, não há como dizer que nossas ações são livres no sentido próprio do termo.

7 Seria muito estranho propor que nossas ações sejam totalmente isentas de alguma restrição ou limite, nesse sentido.

8 A possibilidade da vontade livre, para muitos críticos, seria fruto do desconhecimento da "maioria dos fatores genéticos, psicológicos e sociais que nos influenciam" (KANE, 2005, p. 4, tradução nossa). Poderíamos, por exemplo, nos iludir a ponto de acreditar que não somos totalmente condicionados pela nossa Sociedade ou pelo nosso processo educacional. 9 Para MCKENNA e COATES (2015), essa visão se segue de uma interpretação comum que temos de nós mesmos como deliberadores práticos. Seria essa visão que nos forneceria a possibilidade de ter feito diferente, ao considerar que os eventos passados não impedem a ramificação de possibilidades nos eventos futuros: "A locus of freely willed action arises when the present offers, from an agent's (singular) past, more than one path into the future" (MCKENNA \& COATES, 2015). Essa imagem das ações futuras como uma ramificação, muito conhecida e amplamente utilizada, em inglês forking paths, tem origem no conto do argentino Jorge Luis Borges, intitulado El jardin de senderos que se bifurcan (1941). cf. MCKENNA \& COATES, 2015 e KANE, 2007, pp. 5-6 
É certo que há uma relação entre as ações e as pessoas que realizam essas ações e não há dúvidas quanto a isso. Para o determinista, entretanto, falar em controle é identificar uma causa. É como se houvesse algo dentro do agente pelo qual ele é capaz de agir:

\begin{abstract}
A vontade não é algum mecanismo dentro de mim que eu preciso obter controle. É meu poder, para eu exercer como parecer conveniente, à luz das razões para agir que se apresentam a mim. Quando eu o exerço, estou demonstrando par excellence meu controle sobre minhas ações: é a real fonte daquele controle, não algum meio que eu uso para controlar minhas ações. (LOWE, 2013, p. 167)
\end{abstract}

É o caso de propor uma mudança na compreensão da questão. Se libertarianistas defendem uma noção de escolha genuína por parte dos agentes, embora nem todas as ações sejam exemplificações dessas, por que ainda precisariam apresentar uma explicação de como agentes livres exercem controle sobre suas ações? Sem essa escolha, já não se poderia falar em controle, nem em escolha em um sentido interessante ${ }^{10}$ :

\begin{abstract}
Nossas escolhas, como eu disse, são informadas necessariamente pela nossa propensão às razões para agir, mas são, não obstante, necessariamente livres, no sentido de serem indeterminadas. A noção de escolha livre exercida à luz da razão nos prove com o real paradigma do que é estar 'no controle' das nossas razões. (LOWE, 2008, p. 195)
\end{abstract}

\title{
A causação por agente
}

Para o Determinismo (causal), toda causação pode ser explicada em termos da causação por eventos. A estrutura básica da causação por eventos é $\left[e_{\mathrm{x}}\right.$ causa $\left.e_{\mathrm{y}}\right]$, na qual esta própria estrutura é causada por eventos anteriores. Um exemplo simples desse tipo de causação seria a contida na sentença 'O incêndio causou o colapso do prédio'. Esse incêndio, por sua vez, poderia ser explicado por um vazamento de gás em associação ao mal funcionamento de algum aparelho eletrônico - fatos que também poderiam ser explicados pela causação por eventos -, formando, assim, uma cadeia de explicação. ${ }^{11}$

10 Jonathan Lowe chega a afirmar que seria inadequado exigir do libertarianista uma descrição de como um agente exerce controle sobre suas ações. Cf. LOWE, 2008, p. 195197.

11 Questionar a causação pode ser entendido como uma investigação dos relata envolvidos nessa relação. Ao propor uma alternativa ao modelo da causação por eventos, para explicar ações humanas, por exemplo, é argumentado que ao menos um dos relata não é adequado à 
A causação por agente, por outro lado, é caracterizada não pela ocorrência de um evento, mas pela produção de um evento - entendido como o resultado da ação de um agente. ${ }^{12}$ Tomemos um exemplo proposto por Jonathan Lowe, que apresenta duas situações, a saber, 1) a queda de uma pessoa de um prédio e 2) alguém que pula de um prédio. Ambos são movimentos corporais distintos. Enquanto o primeiro movimento ocorre com a pessoa, o segundo é produzido por ela, ou seja, ela envolve-se ativamente para trazer esse evento à tona:

[S]e a ação de pular de uma pessoa é seu ato de causar certo movimento corporal, sem dúvida, isso não pode ser simplesmente idêntico àquele movimento corporal. [...] [C]omeça agora a parecer duvidável se nós podemos descrever corretamente uma ação tal como essa como sendo absolutamente um evento, uma vez que isso parece ser, ao contrário, o ato de causar um evento por uma pessoa. (LOWE, 2000 , p. 233, grifo do autor, tradução nossa)

O primeiro é um evento e o segundo uma ação, mas como estabelecer essa diferença? Caso tentemos explicar a diferença entre estes dois movimentos corporais através de suas causas, "nós podemos ser tentados a dizer que a diferença deve ser meramente mental" (LOWE, 2000, p. 232, tradução nossa). Essa abordagem consistiria em afirmar que "uma ação de pular é simplesmente um certo movimento corporal, mas um que é causado por um certo tipo de estado mental, ou combinação de estados mentais" (LOWE, 2000, p. 232, tradução nossa). Adotando essa abordagem, entretanto, essas ações poderiam ser novamente explicadas nos termos da causação por eventos.

Se quisermos evitar essa espécie de redução, não basta apenas afirmar que a estrutura da causação por agente é diferente ${ }^{13}$, digamos $\left[A_{1}\right.$ causa $e_{\mathrm{y}}$, pois poderíamos ainda assim oferecer uma forma de explicação que contenha apenas a análise em termos de eventos, por exemplo, ao considerar que um agente, $A$, causa um evento, $e$, "se e somente se existisse algum evento, $x$, tal que $x$ envolveu A e $x$ causou $e$." (LOWE, 2008, p. 123, tradução nossa)

Embora o autor considere que as ações de agentes inanimados

relação em questão. Poderíamos considerar vários itens, no sentido ontológico, para substituir os eventos na explicação, tais como: fatos, agentes, estados de coisas, dentre outros.

12 No que se segue, perceberemos que Jonathan Lowe adota o termo 'agente' em um sentido amplo. Cf. LOWE, 2008, p. 122 e p. 133.

13 Essa estrutura seria a mesma para qualquer tipo de ação realizada por um agente, incluindo as compulsivas e as realizadas com base em coerção. Mas mesmo os defensores da vontade livre defendem que as ações que se seguem desse exercício são distintas das demais. Nem todas as ações são totalmente livres. Cf. KANE, 2005, pp. 59-60. 
possam sofrer essa redução, quando tratamos das ações de animais e seres humanos, interpretaríamos, em alguns casos ao menos, que esses agentes provocaram diretamente suas ações. Consideremos o exemplo oferecido para ilustrar essa diferença:

\begin{abstract}
[Q]uando um agente humano é descrito como tendo acenado sua mão, é sugerido, com isso, que o agente causou um certo tipo de movimento em sua mão: mas nada é insinuado quanto aos meios, caso existam, pelos quais o agente fez isso. De fato, se fôssemos perguntar a tal agente como - no sentido de 'por quais meios', ao invés do sentido 'de que maneira' - ele acenou sua mão, é muito provável que sua resposta seria que ele não fez isso por nenhum meio absolutamente: ele iria, muito provavelmente, responder que ele simplesmente acenou sua mão. (LOWE, 2008, p. 125, grifo do autor, tradução nossa)
\end{abstract}

Ações como a desse exemplo são básicas $^{14}$, pois não haveria uma forma de envolvermos o agente em um evento da forma estabelecida pela afirmação reducionista apresentada acima. Quando perguntamos por que meios uma cartolina foi cortada ou como alguém foi assassinado, o sentido causal desses verbos pode ser facilmente indicado, por exemplo, cortar implica causar separação por meio de uma tesoura e o assassinato de uma pessoa pode ter sido realizado por meio de uma facada. O mesmo, aparentemente, não ocorre com ações como a descrita na passagem acima. Embora possamos dizer, por exemplo, que "Ele, ao querer, levantou o braço", não haveria nada para preencher a lacuna da sentença 'Ele, ao , quis levantar o braço'.

\title{
Substâncias e poderes causais
}

Parte da argumentação consiste em contrariar nosso uso comum da linguagem e afirmar que a relação de causação pode ter agentes - e não apenas eventos - operando como causa. Na proposta de LOWE (2008), a causação por agentes, entendidos como substâncias ${ }^{15}$, é conceitualmente e

14 No decorrer do texto, esperamos que essa passagem se torne mais clara ao leitor: "My own position with regard to voluntary human action is basically this: that when a human agent, $A$, voluntarily causes some event, $e$, A causes $e$ by willing to cause an [...] event. A's so willing - A's volition - is itself an event, but not merely an event: it is an action of $A$ 's indeed, it is a primitive action of $A$ 's, because it is not further analysable in terms of more basic actions of $A$ 's and the consequences of such actions. Willing, in my view, is the most basic kind of action that an intelligent, free agent can perform - it is a species of mental event and, more specifically, an executive act of mind with a determinate intentional content." (LOWE, 2008, p. 7) Sobre as volições e o controle das ações, cf. LOWE, 2013, p. 166-167.

15 Esse tipo de causação é nomeado Substance Causation. Jonathan Lowe dedica o sétimo capítulo de seu livro para esclarecer essa teoria. Grosso modo, a causação é a manifestação 
ontologicamente anterior à causação por eventos. Ao considerarmos a explicação de eventos, perceberíamos que o que realmente ocorre é a ação de uma substância sobre outra.

A ideia central é que as substâncias - consideradas de modo geral -, devido às suas constituições naturais, possuem certos poderes e suscetibilidades causais. Elas manifestam esses poderes ou suscetibilidades ao interagir com outras substâncias. Por exemplo, a água causa a dissolução do cubo de açúcar e o imã causa a atração de um pedaço de ferro. Acompanhemos esta passagem:

\footnotetext{
Parece apropriado dizer que eventos por si mesmos não possuem poderes causais. Apenas objetos persistentes - ou seja, 'substâncias' individuais - possuem poder causal e, de fato, suscetibilidades causais. São tais objetos que nós descrevemos como sendo magnéticos, corrosivos, inflamáveis, solúveis e assim por diante. Objetos manifestam ou exibem seus poderes causais e suscetibilidades ao agir sobre coisas, ou sofrerem a ação de outras coisas, de várias maneiras apropriadas - ao atrair, corroer, queimar, dissolver e assim por diante (LOWE, 2008, p. 138, grifo do autor, tradução nossa)
}

Se a argumentação estiver correta, poderia ser proposto que a causação por eventos seja compreendida em termos da causação por agente. Para Jonathan Lowe, essa opção não é muito explorada, pois, ao pensarmos na noção de agência, nos vem à mente a ideia de ação intencional, ou de um agente racional, e não consideramos pensar em objetos inanimados como substâncias com poderes (e suscetibilidades) causais.

Isso nos levaria a considerar a causação por substâncias de acordo com o princípio abaixo:

\footnotetext{
"Substance $s$ caused event $e 2$ just in case there was some event, $e 1$, and some manner of acting, $F$, such that $e 1$ consisted in $s$ 's $F$ ing and $s$, by Fing, caused $e 2$. ." (LOWE, 2008, p. 146, grifo do autor)
}

O autor deixa claro, entretanto, que, apesar da explicação em termos da causação por substância ser plausível com relação a objetos inanimados (como no exemplo do incêndio), a vontade (livre) não pode ser comparada aos poderes e suscetibilidades causais dos objetos, porque esses não escolhem agir - o açúcar não decide dissolver na água, por exemplo.

$$
* * *
$$

ou exercício de um poder, mas apenas substâncias possuem tais poderes. cf. LOWE, 2008, cap. 7. 
Antes de considerar a perspectiva libertariana de Jonathan Lowe, terminaremos esta seção com um argumento a favor da anterioridade da causação por agente.

A base da diferenciação é apresentada através de um experimento de pensamento. ${ }^{16}$ Somos convidados, inicialmente, a considerar um ser puramente passivo, embora inteligente, que conseguisse registrar os eventos a seu redor. Podemos supor que esse ser hipotético seria capaz de identificar regularidades ou ocorrências entre os eventos em seu campo de visão, mas não seria capaz, aparentemente, de diferenciar quais desses eventos são coincidentes e quais apresentam uma relação causal.

Por sermos agentes capazes de ações intencionais e também cientes do fato de sermos agentes, podemos distinguir quais desses eventos são causais e quais não são, em parte ao menos, devido a nossa experiência. Seria plausível, então, afirmar que possuímos o conceito de causação por agente. Se seguiria que, quando estivermos em dúvida quanto a causalidade de um evento percebido, poderíamos "tentar solucionar essa dúvida por meio da intervenção ativa e da experimentação.” (LOWE, 2008, p. 135, tradução nossa)

\begin{abstract}
Porque nós mesmos somos agentes causais e estamos cientes da nossa habilidade de interferir em e manipular o curso da natureza [...], estamos aptos a testar hipóteses causais experimentalmente e assim nos esforçarmos para distinguir, embora não infalivelmente, entre sequências de eventos causais e não causais. (LOWE, 2008, p. 135, tradução nossa)
\end{abstract}

O ser puramente passivo, imaginado nessa experiência de pensamento, devido a sua impossibilidade de intervir na realidade, não seria capaz de discriminar, empiricamente, entre eventos causais e não causais - e o autor considera que isso seria suficiente para não atribuirmos a esse ser a noção de causalidade por eventos.

Dessa argumentação se seguiria que o conceito de causação por agente é um pré-requisito para a compreensão do conceito de causalidade por eventos. Seria plausível considerar essa anterioridade, pois não parece ser o caso que "nós aprendemos primeiro a aplicar o conceito de causação por evento a eventos observáveis e posteriormente aprendemos a conceber nós mesmos como agentes" (LOWE, 2008, p. 135, grifo do autor, tradução nossa).

\title{
0 libertarianismo de Jonathan Lowe
}

A posição libertariana quanto a vontade livre pode ser abordada como um conjunto de teorias que recusam o determinismo causal, de modo 
que a ação livre não seja compatível com causas suficientes para determinar as escolhas dos agentes. ${ }^{17}$ Robert Kane é visto como um dos principais responsáveis pelo reaparecimento dessa teoria, no final do século passado, embora defenda uma versão da causação por eventos, na qual é o evento da tentativa de um agente realizar uma ação que possui aspectos não deterministas. ${ }^{18}$ Libertarianistas, especialmente com base nos textos de Carl Ginet, não ficariam satisfeitos com essa apresentação. $O$ que ele ou ela gostaria de aceitar, talvez, seja a ideia de que nós, como agentes, devemos estar, metafisicamente, no centro da explicação das ações que exercemos. ${ }^{19}$

Ao invés dessa versão de causação por eventos, David Palmer indica outras duas versões do Libertarianismo. A primeira seria uma espécie de causação por agentes, na qual as ações livres de uma pessoa "são causadas por ela como uma substância, onde causação por substância não é redutível a, nem composta por, causação por eventos ou estados anteriores" (PALMER, 2014, p. 6, tradução nossa), atribuída a Timoth O'Connor. A segunda versão é uma na qual as ações livres não seriam causadas de forma alguma. $^{20}$

A proposta de Jonathan Lowe está mais próxima de Timoth O'Connor do que de Robert Kane, segundo a classificação proposta por PALMER (2014). Ao defender uma teoria volicionista da ação, o filósofo afirma que a ação mais básica que realizamos é a de exercer a vontade. ${ }^{21}$ Nesse sentido, é por querer levantar o braço que o levantamos e não haveria nada mais básico do que isso. ${ }^{22}$ De acordo com Jonathan Lowe, é pelo fato da produção de um evento por um agente não ser um evento, e sim uma ação, que não seria adequado envolver os agentes em uma explicação causal.

17 Nesses termos, essa teoria se enquadraria no chamado Indeterminismo. Entretanto, evitaremos essa associação, já que para esse grupo de teorias algo deve ser indeterminado na produção das ações, o que poderia nos levar a comparar ações intencionais com ações realizadas por acaso ou involuntárias. A consequência seria, inclusive, negativa para o defensor da agência libertariana, já que essa associação, ao invés de favorecer a defesa da vontade livre, poderia comprometê-la. cf. KANE, 2007, p. 9.

18 Seguimos aqui a breve apresentação feita por David Palmer. Cf. PALMER, 2014, pp. 5 6

19 Em nosso entendimento, a proposta de uma teoria da ação não pode ser isenta da apresentação de uma perspectiva sobre como nos entendemos como agentes ou pessoas. A proposta de LOWE (2008) é notável nesse sentido.

20 A teoria de Jonathan Lowe, de fato, representa uma forma de não-causalismo, mas não da forma apresentada por David Palmer.

21 Nas palavras de LOWE (2013, p. 166, grifo do autor), "[a] volition is itself a kind of action - indeed, it is the most primitive or basic kind of action that any agent can perform." 22 Apesar da maioria dos exemplos serem positivos, não podemos deixar de considerar que há o exercício negativo da vontade, a saber, querer não realizar uma ação. Segundo LOWE (2013, p. 164, grifo do autor), "[a]s free human agent [...] I do have a power not to will to raise my arm because I have a power to will not to raise it." 
Com relação à metafísica da ação, a proposta seria afirmar que provocamos alguns eventos diretamente, ficando a explicação dessa ação para questões de racionalidade e não de causalidade. Apesar de longa, a passagem abaixo é esclarecedora:

Suponha que, em uma ocasião específica, um agente humano, $A$, tenha causado um evento $e$, tal como o movimento na mão de $A$, mas que essa instância de causação por agente não seja redutível a uma de causação por evento. Quer dizer, suponha que não seja em virtude de algum evento que cause $e$ que diríamos que $A$ causou $e$. Assim sendo, isso ainda deixa em aberto a questão se ou não algum evento anterior ou eventos foram causas de $e$ e, se assim for, se ou não esse evento anterior ou esses eventos anteriores foram causalmente suficientes para a ocorrência de $e$. Entretanto, é perfeitamente concebível que nenhum evento anterior ou combinação de eventos foi causalmente suficiente para a ocorrência de $e$, mas que a agência de $A$ nessa ocasião foi causalmente necessária para a ocorrência de $e$. Quer dizer, pode ser o caso que se $A$ não tivesse causado $e$, então $e$ não teria ocorrido, já que apenas os eventos anteriores não foram causalmente suficientes para a ocorrência de $e$. [...] $A$ causar $e$ está sujeito somente à explicação racional, não à [explicação] causal. Quer dizer, está em nossas possibilidades dizer que $A$ causou $e$ por uma razão. (LOWE, 2008, p. 129, grifo do autor, tradução nossa)

O evento suposto acima não teria ocorrido sem a agência de $A$. Caso aceitemos que uma ação qualquer não tenha sido suficientemente causada por eventos anteriores, podemos substanciar a argumentação com a distinção entre o que se entende comumente por ações e o que o autor chama de resultados de ações [action-results]. Jonathan Lowe nos informa que não devemos entender os agentes como causas de suas ações, mas "dizer que as ações de uma pessoa consistem quase exclusivamente em que essa pessoa cause certos eventos - eventos que podemos chamar de 'resultados de ações' [action-results]' (LOWE, 2008, p. 148, grifo do autor, tradução nossa). Nossas ações estão relacionadas a possíveis efeitos ou resultados, caso não estejamos impedidos de agir por qualquer motivo. Em todo o caso, não se deveria utilizar o conceito de causa nesses contextos.

Outra distinção interessante, proposta pelo autor, é a relação entre o exercício da vontade e os 'resultados de ações'. Se fôssemos considerar que a ação é realizada ao exercermos a vontade, estaríamos ainda no paradigma da causação de eventos. ${ }^{23}$ Jonathan Lowe concede que podemos entender os eventos que se seguem das nossas ações, os 'resultados de ações', como causados, mas apenas no sentido de resultarem de atos da vontade [acts of

23 É certo, entretanto, que antes de agir é necessário querer. Sobre a consequência do exercício da vontade, cf. LOWE, 2008, p. 150. 
will]. Essa consideração é abordada em detalhes na seguinte passagem:

\begin{abstract}
Um volicionista cuidadoso não diria, em todo o caso, que exercer a vontade é querer que algum evento aconteça: em vez disso, ele diria que é querer fazer alguma coisa, a saber, realizar alguma ação. E é perfeitamente evidente, então, que tal volicionista não está comprometido com a visão que só o que fazemos é, na verdade, querer: pois se queremos fazer algo $e$ não somos impedidos, então temos sucesso em fazê-lo, o que é mais do que apenas querer fazer.
\end{abstract}

Com base nessa passagem, é possível afirmar que "atos da vontade [...] são causas, no sentido da causação por eventos, de todos os resultados de ações das nossas ações voluntárias" (LOWE, 2008, p. 148, tradução nossa), e, ao mesmo tempo, considerar o exercício da vontade como a manifestação de um poder racional e não causal. ${ }^{24} \mathrm{O}$ ato de querer é uma ação e sempre intencional. ${ }^{25}$

O exercício da vontade não é, então, sequer semelhante aos poderes ou suscetibilidades manifestadas pelas substâncias naturais, pois esses são exercidos sem escolha alguma por parte dessas substâncias. Não poderíamos dizer, por exemplo, que o gás escolheu vazar de uma forma específica $x$ ao invés de $y$, com o intuito de espalhar-se pelo prédio e provocar maior impacto à estrutura do mesmo. Os eventos são provocados meramente pela ação de um objeto sobre o outro, pela proximidade ou contato, como no caso do imã ou da dissolução do açúcar.

A conclusão da argumentação apresentada por Jonathan Lowe, na explicação das ações humanas, é estabelecer o exercício da vontade como um caso genuíno de escolha:

\begin{abstract}
O querer [willing] é justamente escolher um curso de ação, normalmente em detrimento a algum outro curso de ação: escolher, digamos, levantar o braço ao invés de deixá-lo abaixado. [...] Concebemos isso como sendo um poder que é caracteristicamente exercido sob a luz da razão (LOWE, 2008, p. 155, grifo do autor, tradução nossa)
\end{abstract}

É por possuir essa característica de ser fundamentada em razões que o exercício da vontade não é um poder causal, mas um poder racional. Se a vontade fosse uma causa, ela não seria propriamente exercida, mas ativada, e não poderíamos falar em racionalidade das ações humanas. A ação só é racional quando o agente a realiza por razões e não quando seu

$24 \mathrm{O}$ filósofo não vê nenhuma dificuldade em aliar uma teoria de causação por substância com uma teoria volicionista. cf. LOWE, 2008, p. 149-150.

25 Podemos aqui distinguir entre um ato e um acontecimento: "Acts of will are events, for they are the doings of substances, namely, of persons. But they are not mere happenings, in the sense that the falling of a stone is a mere happening." LOWE, 2008, p. 173 
comportamento se segue, por assim dizer, delas. ${ }^{26}$

Gostaríamos de finalizar esta seção comentando um pouco mais sobre a vontade como um poder racional ${ }^{27}$.

Jonathan Lowe apresenta o exercício da vontade como um poder espontâneo ${ }^{28}$ A comparação, já bem conhecida, é com a atividade do átomo de rádio. ${ }^{29}$ Essa comparação possui duas dificuldades: 1) A observação sobre a atividade do átomo de rádio é científica, enquanto que a proposta de uma vontade livre se segue, geralmente, da fenomenologia da ação. 2) Não podemos, simplesmente, associar esses dois tipos de poderes, pois, como o próprio LOWE (2008) observa, as condições nas quais exercemos essa capacidade são diferentes daquelas em que o poder (ou suscetibilidade) causal natural é manifestado. ${ }^{30}$

A peculiaridade do tipo de poder que nós manifestamos como agentes racionais é apresentada nesta passagem:

\footnotetext{
Um poder sendo um poder espontâneo não é, evidentemente, uma condição suficiente dele ser um pode racional, como o exemplo da radioatividade do rádio mostra. Mas, eu insisto, é uma condição necessária porque um poder cuja natureza é tal que seu exercício ou manifestação é caracteristicamente determinado, ou mesmo simplesmente feito mais provável, pela influência causal de objetos agindo sobre o possessor do poder não pode, por esta mesma razão, qualificar-se como um poder racional. (LOWE, 2008, p. 155-156, tradução nossa)
}

Agir racionalmente é decidir cursos de ação com base em elementos que justificam (e explicam) nossas ações. Decidir deve ser uma escolha totalmente livre, ou já poderíamos questionar a racionalidade dessas ações.

Nessa argumentação, há uma interessante relação entre a questão da

26 Ao final do artigo, comentaremos sobre essa interessante relação com a teoria das razões para agir.

$27 \mathrm{O}$ autor relaciona esse tipo de poder com o que Aristóteles abordou no livro teta da Metafísica. Cf. LOWE, 2013, p. 165.

28 A argumentação é por eliminação, já que há outros tipos de poderes (e suscetibilidades) causais, como apresentado acima. LOWE (2013), ao distinguir entre diversos tipos de poderes, afirma que por 'espontâneo', ele quer dizer um poder ativo e não causal. Cf. LOWE, 2013, p. 164. Certamente, esse exercício não seria uma ocorrência aleatória ou fora do controle do agente. Cf. LOWE, 2013, p. 166-167.

29 Conferir, por exemplo, LOWE, 2008, p. 150 e LOWE, 2013, p. 153, 159.

$30 \mathrm{Em}$ nossa interpretação, a comparação com a atividade do átomo de rádio serve apenas o propósito de afirmar a concebilidade da produção de um evento sem causas suficientes. Cf. LOWE, 2008, p. 155, 176 e LOWE, 2013, p. 169. 
vontade como um poder racional e a questão das razões para agir. ${ }^{31} \mathrm{O}$ filósofo apresenta o caso de uma pessoa que acredita ser perseguida por alienígenas. $^{32}$ Se fôssemos considerar a crença desse agente hipotético, certamente não avaliaríamos as atitudes tomadas com base nessa crença como racionais. Ao tomarmos ciência da situação, as ações desse agente se tornariam mais compreensíveis, mas não haveria nenhuma razão justificando suas atitudes, já que constataríamos que ninguém o está perseguindo, muito menos alienígenas.

Jonathan Lowe mantém, nesse sentido, que o comportamento causado por crenças ou desejos que compõem a nossa psicologia não pode ser considerado racional, pois não foi baseado em uma escolha. ${ }^{33}$ Acompanhemos essas duas passagens:

Que um agente possui uma crença específica pode ser, mas tipicamente não é, uma razão para o agente agir de um modo específico - mas uma crença tal como essa nunca poderia ser uma razão para uma ação, porque nem é algo na categoria ontológica correta para constituir tal razão. E, embora uma crença possa algumas vezes causar ou ajudar a causar alguns dos comportamentos de um agente, uma ação racional é exatamente uma que não é causada pelas crenças e desejos de um agente. (LOWE, 2008, p. 180-181, grifo do autor, tradução nossa)

Uma ação pode ser conforme a razão, ou razoável, sem ser racional. Para que seja racional, ela deve ser feita por uma razão pela qual o agente escolha livremente agir - ou assim eu afirmo. (LOWE, 2008 p. 182, grifo do autor, tradução nossa)

Em nossa interpretação, Jonathan Lowe compreende os seres humanos como agentes que são racionais por agirem livremente através do exercício da vontade. Essa abordagem parece relacionar dois sentidos do termo 'racional'. O primeiro sugere a existência de "algum padrão (não específico)" (SCHUELER, 2009, p. 103, tradução nossa), que implica a possibilidade de "nem todos viverem de acordo com esse padrão, qualquer

31 É importante frisar que essas seriam as razões normativas.

32 Esse exemplo é uma adaptação de um famoso exemplo proposto por Jonathan Dancy, no livro Practical Reality (2000). Poderíamos alterar o exemplo para qualquer situação na qual alguém está passando por alguma alucinação ou sofrendo efeitos colaterais que provoquem crenças semelhantes.

$33 \mathrm{O}$ autor identifica, corretamente, que uma conhecida teoria da ação, proposta por Donald Davidson, está em completa oposição à sua proposta. Cf. LOWE, 2008, p. 200-202. Para Davidson, as razões são causas e a explicação da ação é alcançada ao identificarmos justamente a causa da ação, que é entendida como um elemento racionalizador da ação, de modo que a "razão pela qual ele realmente agiu foi aquela que realmente o moveu para agir assim, ou seja, aquela que o causou a agir assim." (LOWE, 2008, p. 183, grifo do autor, tradução nossa) 
que seja, pelo menos o tempo todo" (SCHUELER, 2009, p. 103, tradução nossa), que seria o contrário de 'pouco racional' ou 'irracional'; enquanto o segundo, em sentido descritivo, é aquele que avalia as ações em racionais ou não racionais, no sentido de "ser um fato importante sobre os humanos que, mesmo quando eles não vivem de acordo com os padrões de racionalidade, eles ainda são racionais em um modo que outras coisas na natureza não são; eles fazem coisas por razões." (SCHUELER, 2009, p. 103, tradução nossa)

\title{
Considerações finais
}

LOWE (2008) comenta que oferecer uma descrição da agência livre como um caso de escolha genuínamente livre poderia soar alarmes no pensamento naturalista. ${ }^{34} \mathrm{O}$ autor, entretanto, não aborda o dualismo clássico de Descartes, mas uma versão não-cartesiana. O dualismo seria entre uma pessoa e seu corpo. ${ }^{35}$ Uma pessoa (ou self) é um sujeito de experiência, que exibe tanto propriedades físicas e psicológicas, embora não seja identificado a um corpo - uma pessoa e seu corpo possuem condições de persistência distintas. ${ }^{36}$ Essa forma de dualismo não-cartesiano é resumida na seguinte passagem:

\begin{abstract}
Uma pessoa, ou sujeito de experiência, não é [...] idêntica a seu corpo ou a qualquer parte dele e uma pessoa também não deve ser pensada como sendo um espírito imaterial ou alma, nem mesmo uma combinação de corpo e alma. Nessa visão, de fato, não há necessidade de existir tal coisa como almas imateriais. Em vez disso, uma pessoa ou sujeito de experiência deve ser pensado como algo que possui tanto características mentais quanto físicas: algo que sente e pensa, mas que também possui forma, massa e localização no espaço físico. (LOWE, 2000, p. 15 , grifo do autor, tradução nossa)
\end{abstract}

O resultado dessa perspectiva é a afirmação de que as ações não possuem causas puramente físicas. ${ }^{37}$ É certo que precisamos de um corpo capaz de operacionalizar nossas intenções, mas não é por uma taxa de

34 Lowe rejeita o fisicalismo e também afirma não ser um naturalista, ao menos naquilo que o impediria de aceitar que "algumas razões para agir consistam em fatos morais ou estados de coisas" (LOWE, 2008, p. 187, tradução nossa).

35 Trata-se de um dualismo de propriedades. Cf. LOWE, 2008, p. 93-95

36 Cf. LOWE, 2008, p. 147. É evidente que essa distinção é o que permite sua versão do dualismo de propriedades. No capítulo Personal identity and self-knowledge de seu livro An Introduction to the Philosophy of Mind (2000), Jonathan Lowe faz uma série de considerações sobre essa questão. cf. LOWE, 2000, cap. 10.

37 Nas palavras do autor: "Eu não acredito de forma alguma que a vontade humana é um poder físico, mesmo se agentes humanos precisarem possuir determinados poderes físicos em virtude de ter uma vontade eficaz" (LOWE, 2013, p. 169, grifo do autor, tradução nossa) 
sucesso ou habilidade em realizar ações que diríamos que a vontade é eficaz.

O mínimo que a proposta de Jonathan Lowe nos permite é considerar a explicação das ações humanas com base na causalidade exibida por objetos inanimados que não pertencem à "esfera das razões'." (LOWE, 2013, p. 165, tradução nossa) com certa estranheza. Se quisermos continuar a nos entender como seres racionais, não podemos aceitar que ações sejam comportamentos causados e não escolhas baseadas em razões. A compreensão da ação humana comportaria uma sutileza maior do que qualquer modelo oferecido com base na causalidade natural.

Essas considerações seriam suficientes para abordar uma interessante relação entre a proposta de Jonathan Lowe e a teoria das razões para agir em Metaética. ${ }^{38}$ Nosso foco durante o texto esteve voltado para a Filosofia da ação, mas o próprio autor nos informa que começou a adotar o libertarianismo: "uma vez que fui convencido de que apenas uma descrição externalista completa de razões para agir é defensável" (LOWE, 2008, p. v, tradução nossa). Embora não seja possível relacionar diretamente essas teorias, o que temos em mente é considerar se a ausência de um exercício livre da vontade também colocaria em questão as razões que conferem justificação as nossas ações. ${ }^{39}$

Externalistas, em especial realistas morais, defendem que os elementos que conferem justificação às ações não são os estados psicológicos do agente, mas fatos ou estados de coisas ${ }^{40}$, internalistas, por outro lado, associam as razões a estados motivacionais ou elementos conativos. O externalista precisa, segundo críticos, explicar como seria possível aos agentes dissociarem suas ações desses estados psicológicos. Os argumentos de Jonathan Lowe poderiam oferecer suporte a essa explicação.

Retomando o exemplo do alienígena apresentado acima, se não for possível basear ações em razões, o que pressupõe escolha, as ações daquele agente estariam justificadas, uma vez que seriam causadas por algum elemento de sua psicologia. Na ausência de um exercício livre da vontade, o determinismo seria a teoria mais plausível, e nos faria rever, inclusive, o conceito de agente racional.

Acreditamos que Jonathan Lowe, ao propor que a ação racional, que exemplifica o livre exercício da vontade, é aquela baseada em razões, oferece ótimos argumentos para substanciar a defesa do externalismo de

38 O próprio autor comenta que os dois debates "have been carried on relatively independently of each other - in my view, to the detriment of both." LOWE, 2008, p. 199. 39 Muitos filósofos argumentam que a ausência de uma vontade livre influenciaria em nossas considerações sobre a liberdade das ações ou sobre a responsabilidade moral. A proposta que temos em mente poderia substanciar esses argumentos ou seguir como um argumento independente.

40 Cf. LOWE, 2008, p. 181. 
razões em Metaética.

\section{Referências bibliográficas}

CLARKE, Randolph; CAPES, Justin. Incompatibilist (Nondeterministic) Theories of Free Will. The Stanford Encyclopedia of Philosophy. 2015. Disponível em: <http://plato.stanford.edu/entries/incompatibilismtheories/>. Acesso em: 16 jul. 2016.

KANE, Robert. A Contemporary Introduction to Free Will. New York: Oxford University Press, 2005.

Libertarianism. In: FISCHER. John M. et. al. Four Views on Free

Will. Oxford: Blackwell, 2007. p. 5-43.

LOWE, Jonathan. An Introduction to the Philosophy of Mind. New York: Cambridge University Press, 2000.

. Personal Agency: The Metaphysics of Mind and Action. New York:

Oxford University Press, 2008.

Substance Causation, Powers, and Human Agency. In: GIBB S. C.;

LOWE, E. J.; INGTHORSSON, R. D. (Eds.). Mental Causation and Ontology. New York: Oxford University Press, 2013. p. 153-172.

MCKENNA, M.; COATES, D. J. Compatibilism. The Stanford Encyclopedia of Philosophy. 2015. Disponível em: <http://plato.stanford.edu/entries/compatibilism/>. Acesso em: 16 jul. 2016. O'CONNOR, Timothy. Agent-Causal Theories of Freedom. In: KANE, Robert (Ed.). The Oxford Handbook of Free Will. $2^{\circ}$ ed. New York: Oxford University Press, 2011. p. 309-328.

PALMER, David. Free Will, Libertarianism and Kane. In: PALMER, David. Contemporary Debates. New York: Oxford University Press, 2014. p. 3-14.

SCHUELER, George. The Humean theory of motivation rejected. Philosophy and Phenomenological Research, v. 78, n. 1, p. 103-122, Jan. 2009. 